\title{
Article \\ Exploring the Associations between Perceived Organizational Support and Job Burnout among Chinese Academic Journal Editors: A Moderated Mediation Model
}

\author{
Xiaoyan $\mathrm{Yu}^{1,+}$, Shiyong $\mathrm{Wu}^{2, *}\left(\mathbb{1}\right.$, Wei Chen ${ }^{3, *}$, Wen Zheng ${ }^{3,+}$, Mingxi Huang ${ }^{4,+}$, Lei Yang ${ }^{5,+}$ and Shuyi Zhou ${ }^{6,+}$ \\ 1 Editorial Office of Modern Education Journal, South China Normal University, Guangzhou 510631, China; \\ xiaoyan.yu@m.scnu.edu.cn \\ 2 South China Vocational Education Research Centre, South China Normal University, Foshan 528225, China \\ 3 School of Education, Huizhou University, Huizhou 516000, China; zhengwen@hzu.edu.cn \\ 4 School of Education, South China Normal University, Guangzhou 510631, China; \\ huangmingxi@m.scnu.edu.cn \\ 5 School of Vocational Educational Teacher, Guangdong Polytechnic Normal University, \\ Guangzhou 510665, China; echoyang@m.scnu.edu.cn \\ 6 Faculty of Foreign Language, Dongguan Science \& Technology School, Dongguan 523470, China; \\ 2019023366@m.scnu.edu.cn \\ * Correspondence: shiyong.wu@m.scnu.edu.cn (S.W.); chenwei@m.scnu.edu.cn (W.C.) \\ + Authors are equally contributed to this work.
}

Citation: Yu, X.; Wu, S.; Chen, W.; Zheng, W.; Huang, M.; Yang, L.; Zhou, S. Exploring the Associations between Perceived Organizational Support and Job Burnout among Chinese Academic Journal Editors: A Moderated Mediation Model. Int. J. Environ. Res. Public Health 2021, 18, 12167. https://doi.org/10.3390/ ijerph182212167

Academic Editors: Inah Kim, Tae-Won Jang, Chunhui Suh and Wanhyung Lee

Received: 9 September 2021

Accepted: 18 November 2021

Published: 19 November 2021

Publisher's Note: MDPI stays neutral with regard to jurisdictional claims in published maps and institutional affiliations.

Copyright: () 2021 by the authors. Licensee MDPI, Basel, Switzerland. This article is an open access article distributed under the terms and conditions of the Creative Commons Attribution (CC BY) license (https:// creativecommons.org/licenses/by/ $4.0 /)$.

\begin{abstract}
Background: Job burnout (JB) has become a prevalent emotional and psychological syndrome across diverse contexts, especially in the face of the COVID-19 pandemic. This study aimed to examine the relationship between perceived organizational support (POS), job satisfaction (JS), self-efficacy (SE), and JB, alongside their mechanism of interplay. Methods: We took 210 Chinese academic journal editors as the research participants and designed a moderated mediation model to examine the posited construct. All the data were gathered online and analyzed with the statistical software SPSS and SmartPLS. Results: The participants comprised 117 women $(55.71 \%)$ and 93 men $(44.29 \%)$. There were significant differences among observed variables in age, experience, and title. POS had a significant negative predictive effect on JB $(95 \% \mathrm{CI}=-0.43 ;-0.06)$. JS mediated the relationship between POS and JB $(95 \% \mathrm{CI}=-0.48 ;-0.11)$. SE moderated the association between JS and JB $(95 \% \mathrm{CI}=0.04 ; 0.75)$ but did not function as a moderator in the relationship between POS and JS $(95 \% \mathrm{CI}=-0.01 ; 0.24)$. Conclusions: POS, JS, and SE were crucial determinants of JB among Chinese academic journal editors. Targeted interventions should be initiated to diminish editors' feelings of being unappreciated, inefficient, dissatisfied, and unaccomplished at work.
\end{abstract}

Keywords: perceived organizational support; job burnout; job satisfaction; self-efficacy; Chinese academic journal editors; COVID-19

\section{Introduction}

Burnout, widely characterized by three related, but empirically distinct, componentsexhaustion, depersonalization, and reduced professional efficacy [1,2] —is an emotional and psychological syndrome prevalent throughout a variety of work contexts and job roles, such as the sport, education, parenting, and public service sectors [1,3-6]. Job burnout (JB) is influenced by a complex interplay between organizational and individual characteristics [6] Concerning the organizational factor, an employee's perceived organizational support (POS) has been significantly linked to decreasing levels of burnout [7]. Regarding the individual factors, personal attitude toward the whole job situation (e.g., job satisfaction, JS) and belief (e.g., self-efficacy, SE) have also been negatively associated with burnout $[1,8]$.

POS refers to employees' perceptions of the extent that their contributions are appreciated and their wellbeing is cared for by their organization [9]. Several burnout studies 
have shown that POS functions as a predictor of JB among health workers in Turkey [10], Chinese policemen [11], and Saudi Arabian healthcare staff [12]. JS is widely defined by Locke [13] as "a pleasurable or positive emotional state resulting from the appraisal of one's job and job experience" and involves three dimensions: intrinsic, extrinsic, and general reinforcement [14]. Previous studies have also shown that JS is negatively related to JB [15-18]. SE refers to people's judgments regarding their ability to succeed in a particular situation [19]. Employees with high SE are more effective at coping with negative emotions caused by work stress, such as JB.

Additionally, some theoretical and empirical studies have identified the interrelationship between those predictors of JB. According to social exchange theory (e.g., $[20,21])$, POS is a critical contributor to JS. Some researchers have noted that employees' perceived and received organizational support positively predicts their levels of JS [22,23]. Moreover, according to the job demands-resources (JDR) model [24], when perceiving inefficient job resources (e.g., organizational support), employees tend to mobilize individual resources (e.g., SE) and are more likely to be satisfied with their work. Furthermore, some studies have demonstrated that SE controls the association between POS and JS [25,26], with a significantly negative relationship between SE, JS, and JB $[3,27,28]$.

As part of a typical public service industry, academic journal editing is a stressful profession that involves numerous articles in print [29] alongside constant worries about accuracy in content and grammar [30,31], which can ultimately lead to job dissatisfaction [29] and JB [32]. This situation is similarly severe in the Chinese setting. Some Chinese scholars have identified that insufficient organizational support can lead to JB among this cohort [33]. In addition, Yu and Zhang [34] noted that emotional exhaustion had a significant effect on scientific journal editors' physical and mental health and that JB was negatively related to their JS. Yao et al. [35] also found that editors' mental health was positively associated with the level of support they received and was negatively associated with JB.

These previous studies have greatly enriched our understanding of people's experiences with JB and its antecedents. However, these representative determinants affecting JB have not yet been integrated into a synthetic model that can identify individual and organizational factors. Specifically, little attention has been paid to the interaction between POS, JS, SE, and JB. More importantly, with the continuous spread of the COVID-19 pandemic and its restrictions, psychological problems, including burnout, have been further exacerbated [36-39]. Compared to those working in other disciplines, academic journal editors may suffer higher risks of burnout because of the precariousness of their position, defined by the ease of losing high-quality, article-format original scholarship and/or readership due to editing missteps [40]. Hence, there is great significance in investigating the influence of POS, JB, and SE on JB among academic journal editors facing the COVID-19 scenario.

The purpose of this study was to measure the predictive effects of POS, JS, and SE on $\mathrm{JB}$, and explore the mechanisms at play among Chinese academic journal editors in the context of the COVID-19 outbreak. This study will add value to the theoretical literature on burnout constructs by assessing the complex relationship between JB and its correlations in a sample composed of Chinese academic journal editors. The following hypotheses were assumed:

Hypotheses 1 (H1). POS negatively predicts JB.

Hypotheses 2 (H2). JS mediates the association between POS and JB.

Hypotheses 3 (H3). SE moderates the mediating impact of JS on the link between POS and JB.

The complete hypothesized model is presented in Figure 1. 


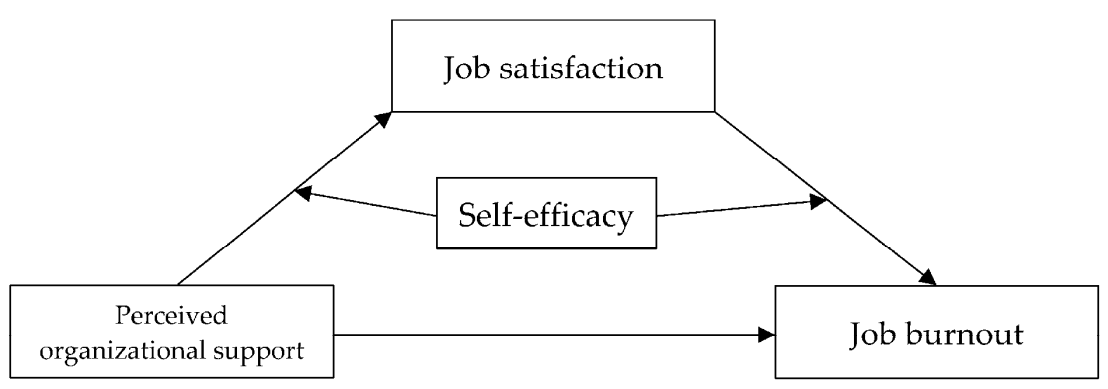

Figure 1. Posited model.

\section{Materials and Methods}

\subsection{Participants}

All participants were recruited online via each author's social media (e.g., WeChat and email) due to the social-distancing restrictions under the COVID-19 pandemic. We first incorporated these four measures into a single file and then input the measures into the Wenjuanxing Online Survey Software, known as Chinese Qualtrics, so that participants could fill out the survey at any time and in any place. After the participants had completed the questionnaire, we examined the validity of the data and confirmed that all data collected between March and June 2021 were of high quality. Ultimately, 210 Chinese academic journal editors were included in our study.

\subsection{Measures}

\subsubsection{Perceived Organizational Support Scale}

POS was calculated by the Chinese version of the eight-item scale extracted by Settoon et al. [41] from the short version of the Survey of Perceived Organizational Support used to evaluate the employee perception of the organization and actions that could affect their wellbeing [9]. Responses were rated on a 5-point Likert-type scale from 1 = strongly disagree to 5 = strongly agree. A sample item was "My organization cares about my opinions." Higher scores reflect a higher level of POS. The Cronbach's alpha for the English version was 0.94 [41,42], compared to a value of 0.83 for the Chinese version [43]. In the present study, the alpha coefficient is 0.89 .

\subsubsection{Job Burnout Scale}

JB was gauged with the Chinese version of the Maslach Burnout Inventory-Human Services Survey (MBI-HSS) originally developed by Maslach et al. [2] and comprised 22 items. As the most commonly adopted instrument for assessing occupational burnout, MBI-HSS consists of three subscales: emotional exhaustion (EE), depersonalization (DP), and personal accomplishment (PA). Responses are rated on a 7-point Likert-type scale ( 0 = never to $6=$ everyday). Participants were asked to rate their agreements with statements such as "I feel burned out from my work." Higher scores on the EE, DP, and diminished PA indicated a higher level of burnout. The Chinese version of the MBI-HSS has shown good reliability and validity in a Chinese context (e.g., [44,45]). The present study's inter-item consistencies for EE, DP, PA, and the total items were $0.92,0.85,0.75$, and 0.87 , respectively.

\subsubsection{Job Satisfaction Scale}

JS was assessed with the Chinese version of the Minnesota Satisfaction Questionnaire Short Form (MSQ-SF), originally constructed by Weiss, Dawis, and England [14], consisting of 20 items that examine "how people feel about different aspects of their jobs." [46,47]. The MSQ-SF has three dimensions: intrinsic (12 items), extrinsic (8 items), and general (total items). Responses were rated on a 5-point Likert-type scale ( $1=$ not satisfied, $5=$ extremely satisfied). Participants were asked to rate their level of satisfaction with statements such as "The opportunities to work alone." In this model, higher total scores indicate higher satisfaction with work. The Cronbach's alphas of the original version's ranges are $0.84-0.91$, 
$0.77-0.82$, and $0.87-0.92$ for intrinsic, extrinsic, and general, respectively [14,48]. By contrast, the Cronbach's alphas of the Chinese version's scale ranges are 0.90-0.92, 0.83-0.84, and 0.91-0.93 for intrinsic, extrinsic, and general, respectively [49,50]. In the present study, the Cronbach's alphas for the total, intrinsic, and extrinsic job satisfaction were determined as $0.94,0.90$, and 0.88 , respectively.

\subsubsection{Self-Efficacy Scale}

SE was measured with the Chinese version of the General Self-efficacy Scale (GSES), comprising ten items that investigate people's self-beliefs in difficulties or dilemmas [51-53]. Responses were rated on a 4-point Likert-type scale $(1=$ absolutely incorrect, $4=$ absolutely correct). Participants were asked to rate their degree of agreement with statements such as "I always succeed in solving the problem once I try my best." In this model, higher scores indicate a higher sense of efficacy. The Cronbach's alphas of the original version range from 0.75 to 0.91 [54,55], compared to 0.92 for the Chinese version [51,56]. In this study, the Cronbach's alpha reliability coefficient was found to be 0.93 .

\subsection{Data Analysis}

We deployed SmartPLS 3.3.2, the most widely used partial least square (PLS) statistical analysis software, and the PROCESS macro in SPSS to analyze the data. As our study relied on self-reported measures, we first checked the common method variance (CMV) using Harman's one-factor test [57]. The outcomes indicated that the single factor solution explained only $35.23 \%$ of the variance (less than the recommended $40 \%$ threshold). Therefore, common method bias did not occur in this study. Multicollinearity was also assessed using the variance inflation factor (VIF). The results indicated that none of the variables exceeded the cut-off value of 5 suggested by Hair et al. [58]. The issue of CMV was, therefore, absent. Then, we evaluated the psychometric properties of the posited model by testing the reliability, convergent validity, and discriminant validity of the measurements. To improve the model's satisfactory level, we retained the items with factor loadings exceeding 0.7 for further analysis [59]. Finally, the moderated mediation hypothesis was evaluated using a bootstrapping procedure with 5000 subsamples in PROCESS Model 58 [60]. We also produced a simple slope to display the difference in the conditional indirect effects across different levels of the moderator. The diagram indicated that significant effects were supported by the absence of zero within the confidence intervals.

\subsection{Ethics}

This study was examined and authorized by the South China Normal University Academic Ethics Committee. The research ethics approval was attached to the explanatory statement, and a consent form was supplied to the participants.

\section{Results}

\subsection{Characteristics of Participants}

The participants comprised 117 women (55.71\%) and 93 men (44.29\%). The ages of $72.38 \%$ of participants ranged from 31 to 50 years old. Years of work experiences spanned $1-5(20.5 \%), 6-10(31.4 \%), 11-20(31.9 \%)$, and above $20(16.2 \%)$ years. The majority of the participants $(74.76 \%$ ) obtained post-graduate degrees (M.A. $=49.05 \%$, Ph.D. $=25.71 \%$ ). Participants with the titles of professor, associate professor, lecturer, and primary accounted for $12.9 \%, 36.2 \%, 39.0 \%$, and $11.9 \%$ of the total, respectively. The work contracts of the participants were both long-term (70\%) and fixed-term (30\%). Over half the participants worked as full-time editors (54.8\%), compared with the dual roles of teacher-editor $(27.1 \%)$ and manager-editor $(18.1 \%)$. The journals employing the participants were found to be affiliated with universities (58.1\%), research institutes $(20 \%)$, industries $(11.4 \%)$, and academic associations (10.5\%). More detailed demographical information about journal publication scopes, categories, and metrics is provided in Table 1. 
Table 1. Characteristics of study participants.

\begin{tabular}{|c|c|c|c|}
\hline Characteristics & Sub-Characteristics & Number & Percentage \\
\hline \multirow[b]{2}{*}{ Gender } & Male & 93 & $44.3 \%$ \\
\hline & Female & 107 & $55.7 \%$ \\
\hline \multirow{4}{*}{ Age } & $20-30$ & 20 & $9.5 \%$ \\
\hline & $31-40$ & 80 & $41.9 \%$ \\
\hline & $41-50$ & 64 & $30.5 \%$ \\
\hline & Over 50 & 38 & $18.1 \%$ \\
\hline \multirow{4}{*}{ Experience } & $1-5$ & 43 & $20.5 \%$ \\
\hline & $6-10$ & 66 & $31.4 \%$ \\
\hline & $11-20$ & 67 & $31.9 \%$ \\
\hline & Over 20 & 34 & $16.2 \%$ \\
\hline \multirow{4}{*}{ Degree } & Doctorate & 54 & $25.7 \%$ \\
\hline & Master's & 103 & $49.0 \%$ \\
\hline & Bachelor's & 50 & $23.8 \%$ \\
\hline & College & 3 & $1.4 \%$ \\
\hline \multirow{4}{*}{ Title } & Professor & 27 & $12.9 \%$ \\
\hline & Associate professor & 76 & $36.2 \%$ \\
\hline & Lecturer & 82 & $39.0 \%$ \\
\hline & Primary & 25 & $11.9 \%$ \\
\hline \multirow{3}{*}{ Role } & Editor & 115 & $54.8 \%$ \\
\hline & Teacher and Editor & 57 & $27.1 \%$ \\
\hline & Manager and Editor & 38 & $18.1 \%$ \\
\hline \multirow{4}{*}{ Affiliation } & University & 122 & $58.1 \%$ \\
\hline & Institute & 42 & $20.0 \%$ \\
\hline & Industry & 24 & $11.4 \%$ \\
\hline & Association & 22 & $10.5 \%$ \\
\hline \multirow{2}{*}{ Contract } & Long term & 146 & $69.5 \%$ \\
\hline & Fixed term & 64 & $30.5 \%$ \\
\hline \multirow{3}{*}{ Discipline } & Social science & 79 & $37.6 \%$ \\
\hline & Nature science & 81 & $38.6 \%$ \\
\hline & Cross-discipline & 50 & $23.8 \%$ \\
\hline \multirow{3}{*}{ Category } & Multiple & 46 & $21.9 \%$ \\
\hline & Specific & 117 & $55.7 \%$ \\
\hline & University journals & 47 & $22.4 \%$ \\
\hline \multirow{3}{*}{ Metrics } & Chinese Top-tier & 114 & $54.3 \%$ \\
\hline & Web of Science Core Collection & 8 & $3.8 \%$ \\
\hline & Others & 88 & $41.9 \%$ \\
\hline
\end{tabular}

\subsection{Descriptive Statistics}

Table 2 presents the minimum values, maximum values, means, and standard deviations of variables. Editors obtained slightly higher scores than the median in POS and SE, indicating that they perceived high support from organizations and feelings of self-efficiency in work tasks. Similarly, the average JS of editors was higher than the median, meaning that the participants were, overall, satisfied with their jobs, especially at an intrinsic level, including factors such as job stability, responsibility, and self-directiveness. In terms of JB, the average value of editors was close to the median, which indicated that the participants had experienced medium job-related burnout, particularly JB due to emotional exhaustion and diminishing self-accomplishment. 
Table 2. Minimum, maximum, average, and standard deviation of variables and sub-variables.

\begin{tabular}{lcccc}
\hline \multicolumn{1}{c}{ Variables } & Minimum & Maximum & Average & Standard Deviation \\
\hline Perceived organizational support & 1.25 & 5 & 3.22 & 0.71 \\
Job satisfaction & 1.6 & 5 & 3.35 & 0.57 \\
$\quad$ Intrinsic satisfaction & 1.83 & 5 & 3.47 & 0.56 \\
$\quad$ Extrinsic satisfaction & 1.25 & 5 & 3.18 & 0.67 \\
Self-efficacy & 1.1 & 4 & 2.6 & 0.55 \\
Job burnout & 0.64 & 4.91 & 2.44 & 0.83 \\
Emotional Exhaustion & 0 & 6 & 2.52 & 1.3 \\
Depersonalization & 0 & 6 & 1.69 & 1.21 \\
Low personal accomplishment & 0.13 & 5.13 & 2.82 & 0.95 \\
\hline
\end{tabular}

Table 3 shows the significant differences observed between age, experience, and title. Regarding age differences, participants over 50 years old had the highest scores for JS and SE. The youngest participants, aged between 20 and 30 years old, scored highest for POS, while the cohort between 31 and 40 years old obtained the highest scores for JB, with the only significant difference $(p=0.01)$. In terms of experience, participants with the least work experience gained the highest scores for POS and SE, and editors over 20 years old scored the highest for JS. Participants who had 6 to 10 years of work experiences obtained the highest scores for JB, but significant differences were observed only for the latter two variables ( $p=0.05$ and 0.01 ). Regarding title, participants with professor-level titles gained the highest scores for JS and SE, while those who were awarded a primary title scored the highest for POS and JB. However, the difference was only significant for SE $(p=0.04)$. There were no significant differences found for the other control variables.

Table 3. Significant differences in perceived organizational support, job satisfaction, self-efficacy, and job burnout in age, experience, and title.

\begin{tabular}{|c|c|c|c|c|c|c|c|c|c|c|c|c|c|c|c|c|c|c|c|c|c|c|c|c|c|c|c|c|c|c|}
\hline \multirow{3}{*}{ Variables } & \multicolumn{10}{|c|}{ Age } & \multicolumn{10}{|c|}{ Experience } & \multicolumn{10}{|c|}{ Title } \\
\hline & \multicolumn{2}{|c|}{$\begin{array}{c}20-30 \\
(n=20)\end{array}$} & \multicolumn{2}{|c|}{$\begin{array}{c}31-40 \\
(n=88)\end{array}$} & \multicolumn{2}{|c|}{$\begin{array}{c}41-50 \\
(n=64)\end{array}$} & \multicolumn{2}{|c|}{$\begin{array}{c}50 \text { Above } \\
(n=38)\end{array}$} & \multirow[t]{2}{*}{$F$} & \multirow{2}{*}{ Sig. } & \multicolumn{2}{|c|}{$\begin{array}{c}1-5 \\
(n=43)\end{array}$} & \multicolumn{2}{|c|}{$\begin{array}{c}6-10 \\
(n=66)\end{array}$} & \multicolumn{2}{|c|}{$\begin{array}{c}11-20 \\
(n=67)\end{array}$} & \multicolumn{2}{|c|}{$\begin{array}{c}20 \text { Above } \\
(n=34)\end{array}$} & \multirow[t]{2}{*}{$F$} & \multirow{2}{*}{ Sig. } & \multicolumn{2}{|c|}{$\begin{array}{l}\text { Professor } \\
(n=27)\end{array}$} & \multicolumn{2}{|c|}{$\begin{array}{c}\mathrm{A} / \mathrm{P} \\
(n=76)\end{array}$} & \multicolumn{2}{|c|}{$\begin{array}{l}\text { Senior } \\
(n=82)\end{array}$} & \multicolumn{2}{|c|}{$\begin{array}{l}\text { Primary } \\
(n=25)\end{array}$} & \multirow[t]{2}{*}{$F$} & \multirow{2}{*}{ Sig. } \\
\hline & $M$ & $S D$ & $M$ & $S D$ & $M$ & $S D$ & $M$ & $S D$ & & & $M$ & $S D$ & $M$ & $M$ & $S D$ & $M$ & $S D$ & $M$ & & & $M$ & $S D$ & $M$ & $S D$ & $M$ & $S D$ & $M$ & $S D$ & & \\
\hline POS & 3.29 & 0.63 & 3.21 & 0.78 & 3.21 & 0.68 & 3.22 & 0.68 & 0.07 & 0.98 & 3.34 & 0.65 & 3.05 & 0.7 & 3.3 & 0.74 & 3.22 & 0.71 & 1.93 & 0.13 & 3.22 & 0.78 & 3.21 & 0.73 & 3.17 & 0.69 & 3.40 & 0.67 & 0.64 & 0.59 \\
\hline JS & 3.27 & 0.63 & 3.33 & 0.57 & 3.32 & 0.58 & 3.51 & 0.51 & 1.3 & 0.28 & 3.38 & 0.59 & 3.2 & 0.52 & 3.43 & 0.59 & 3.47 & 0.54 & 2.66 & $0.05^{*}$ & 3.53 & 0.64 & 3.37 & 0.57 & 3.28 & 0.53 & 3.35 & 0.60 & 0.70 & 0.55 \\
\hline $\mathrm{SE}$ & 2.6 & 0.59 & 2.55 & 0.53 & 2.58 & 0.59 & 2.75 & 0.52 & 1.21 & 0.31 & 2.67 & 0.62 & 2.5 & 0.55 & 2.62 & 0.52 & 2.66 & 0.53 & 1.11 & 0.35 & 2.87 & 0.58 & 2.60 & 0.56 & 2.54 & 0.52 & 2.51 & 0.54 & 2.74 & 0.04 * \\
\hline $\mathrm{JB}$ & 2.54 & 0.56 & 2.56 & 0.88 & 2.48 & 0.8 & 2.03 & 0.77 & 4.05 & $0.01 * *$ & 2.47 & 0.82 & 2.69 & 0.82 & 2.28 & 0.85 & 2.21 & 0.72 & 3.84 & $0.01^{*}$ & 2.27 & 0.88 & 2.39 & 0.79 & 2.49 & 0.79 & 2.60 & 1.01 & 0.86 & 0.46 \\
\hline
\end{tabular}

\subsection{Correlation Analysis}

Table 4 presents the correlations between the investigated variables and the Cronbach's alpha coefficients of the scales. All the dimensions were significantly correlated with each other. The correlations were positive and significant for POS, JS, and SE $(p<0.01)$. JB was negatively significantly related with the other variables $(p<0.01)$. The two dimensions of JS both positively significantly predicted JS. All three dimensions of JB also positively significantly predicted JB, but low personal accomplishment was unrelated to emotional exhaustion and depersonalization. This result confirmed the suggestion that the professional efficacy subscale is weakly linked to the other two subscales and can be used separately $[1,2,61]$.

\subsection{Measurement Model Test}

The measurement model was evaluated using the following criteria: factor loadings, composite reliability, Cronbach's alpha, and average variance extracted (AVE), as suggested by Roldán and Sánchez-Franco [62]. The threshold values for factor loading, composite reliability, Cronbach's alpha, and AVE are recommended to be greater than 0.7 [63], 0.7, 0.7, and 0.5 , respectively [64]. However, MacCallum et al. [65,66] argued that an item value over 0.60 in a factor model with a small sample size is acceptable. Together, covering all dimensions, except for the low personal accomplishment factor loading exceeding 0.6, 
factors with values over 0.7 were extracted as observed variables, as shown in Table 5 . The internal consistency reliabilities of latent variables ranged from 0.88 to 0.94 for Cronbach's alpha and from 0.91 to 0.95 for composite reliabilities. All AVE values were also above the recommended 0.5 cut-off thresholds. Therefore, the modified measurement model presented adequate convergent validity.

Table 4. Correlations of variables and sub-variables.

\begin{tabular}{|c|c|c|c|c|c|c|c|c|c|}
\hline Variables & 1 & 2 & 3 & 4 & 5 & 6 & 7 & 8 & 9 \\
\hline Perceived organizational support & $(0.90)$ & & & & & & & & \\
\hline Job satisfaction & $0.71 * *$ & $(0.94)$ & & & & & & & \\
\hline Intrinsic satisfaction & $0.62 * *$ & $0.95 * *$ & $(0.90)$ & & & & & & \\
\hline Extrinsic satisfaction & $0.73^{* *}$ & $0.92 * *$ & $0.76^{* *}$ & $(0.88)$ & & & & & \\
\hline Self-efficacy & $0.32 * *$ & $0.48^{* *}$ & $0.53^{* *}$ & $0.35 * *$ & $(0.93)$ & & & & \\
\hline Job burnout & $-0.48^{* *}$ & $-0.51^{* *}$ & $-0.50 * *$ & $-0.45^{* *}$ & $-0.45^{* *}$ & $(0.87)$ & & & \\
\hline Emotional Exhaustion & $-0.46^{* *}$ & $-0.43^{* *}$ & $-0.38^{* *}$ & $-0.43^{* *}$ & $-0.29 * *$ & $0.86^{* *}$ & $(0.92)$ & & \\
\hline Depersonalization & $-0.33^{* *}$ & $-0.30^{* *}$ & $-0.29 * *$ & $-0.27^{* *}$ & $-0.21^{* *}$ & $0.79 * *$ & $0.67 * *$ & $(0.85)$ & \\
\hline Low personal accomplishment & $-0.19^{* *}$ & $-0.33^{* *}$ & $-0.39 * *$ & $-0.21^{* *}$ & $-0.48^{* *}$ & $0.44 * *$ & -0.00 & 0.08 & $(0.75)$ \\
\hline
\end{tabular}

** $p<0.01$; Cronbach's alpha coefficients are presented in parentheses diagonally.

Table 5. Factor loading, Cronbach's alpha, composite reliability, and average variance of the items extracted from the variables.

\begin{tabular}{|c|c|c|c|c|c|}
\hline Constructs & Items & Factor Loading & Cronbach & $\begin{array}{l}\text { Composite } \\
\text { Reliability }\end{array}$ & $\begin{array}{c}\text { Average Variance } \\
\text { Extracted }\end{array}$ \\
\hline \multirow{6}{*}{$\begin{array}{c}\text { Perceived } \\
\text { organizational } \\
\text { support }\end{array}$} & Perceived organizational support 1 & 0.82 & \multirow{6}{*}{0.88} & \multirow{6}{*}{0.91} & \multirow{6}{*}{0.63} \\
\hline & Perceived organizational support 2 & 0.83 & & & \\
\hline & Perceived organizational support 3 & 0.88 & & & \\
\hline & Perceived organizational support 5 & 0.74 & & & \\
\hline & Perceived organizational support 7 & 0.76 & & & \\
\hline & Perceived organizational support 8 & 0.74 & & & \\
\hline \multirow{9}{*}{ Job satisfaction } & Intrinsic 4 & 0.73 & \multirow{9}{*}{0.91} & \multirow{9}{*}{0.92} & \multirow{9}{*}{0.54} \\
\hline & Intrinsic 7 & 0.71 & & & \\
\hline & Intrinsic 9 & 0.77 & & & \\
\hline & Intrinsic 10 & 0.79 & & & \\
\hline & Intrinsic 11 & 0.75 & & & \\
\hline & Intrinsic 12 & 0.81 & & & \\
\hline & Extrinsic 2 & 0.75 & & & \\
\hline & Extrinsic 3 & 0.76 & & & \\
\hline & Extrinsic 8 & 0.70 & & & \\
\hline \multirow{8}{*}{ Self-efficacy } & Self-efficacy 1 & 0.75 & \multirow{8}{*}{0.94} & \multirow{8}{*}{0.95} & \multirow{8}{*}{0.69} \\
\hline & Self-efficacy 4 & 0.78 & & & \\
\hline & Self-efficacy 5 & 0.84 & & & \\
\hline & Self-efficacy 6 & 0.85 & & & \\
\hline & Self-efficacy 7 & 0.87 & & & \\
\hline & Self-efficacy 8 & 0.86 & & & \\
\hline & Self-efficacy 9 & 0.87 & & & \\
\hline & Self-efficacy 10 & 0.81 & & & \\
\hline \multirow{9}{*}{ Job burnout } & Emotional exhaustion 3 & 0.87 & \multirow{9}{*}{0.93} & \multirow{9}{*}{0.95} & \multirow{9}{*}{0.78} \\
\hline & Emotional exhaustion 4 & 0.89 & & & \\
\hline & Emotional exhaustion 5 & 0.93 & & & \\
\hline & Emotional exhaustion 6 & 0.82 & & & \\
\hline & Emotional exhaustion 7 & 0.90 & & & \\
\hline & Depersonalization 2 & 0.70 & & & \\
\hline & Depersonalization 3 & 0.67 & & & \\
\hline & Lack of Personal Accomplishment 4 & 0.61 & & & \\
\hline & Lack of Personal Accomplishment 7 & 0.60 & & & \\
\hline
\end{tabular}

Discriminant validity was also considered an essential index for testing the adequacy of the measurement model. SmartPLS 3.3 provides the heterotrait-monotrait (HTMT) ratio of correlations to assess discriminant validity. In accordance with Henseler et al. [67], the HTMT value should be below 0.85. The results indicated that all HTMT ratios between the two constructs were less than the recommended value (see Table 6). Hence, each construct was considered valid and distinct from other constructs. 
Table 6. Heterotrait-monotrait (HTMT) discrimination validity of the measurement model.

\begin{tabular}{ccccc}
\hline Variables & $\mathbf{1}$ & $\mathbf{2}$ & $\mathbf{3}$ & $\mathbf{4}$ \\
\hline Perceived & - & & & \\
organizational support & 0.79 & - & & \\
Job satisfaction & 0.32 & 0.46 & - & - \\
Self-efficacy & 0.55 & 0.56 & 0.49 & \\
Job burnout & & & \\
\hline
\end{tabular}

\subsection{Structural Model Test}

The structural model was assessed by the following parameters using SmartPLS 3.3: the goodness of fit $(\mathrm{GoF})$ indices, path coefficient, and $t$-value. The GoF criteria included the standardized root-mean-square residual (SRMR, $<0.1$ suggested by Kline [68]), squared Euclidean distance (d_ULS) and geodesic distance (d_G) $(>0.05$ recommended by Dijkstra and Henseler [69]), normed fit index (NFI, $>0.8$ advised by Hooper et al. [70]), and root mean squared residual covariance (RMS_theta, $<0.12$ advocated by Henseler et al. [71]). The statistical outcomes indicated that the estimated structural model had an appropriate model fit index (see Table 7).

Table 7. Fit indices of the structural model.

\begin{tabular}{cccccc}
\hline Fit index & SRMR & d_ULS & d_G & NFI & RMS_theta \\
\hline Proposed value & $<0.10$ & $>0.05$ & $>0.05$ & $>0.80$ & $<0.12$ \\
Estimated value & 0.07 & 2.21 & 0.93 & 0.85 & 0.10
\end{tabular}

SRMR: standardized root mean square residual, d_ULS: squared Euclidean distance, d_G: geodesic distance, NFI normed fit index, RMS_theta: root mean squared residual covariance.

According to Chin [72], the path coefficient beta value should be greater than 0.2 , and the value of the $t$-statistics should be greater than 1.96. For convenience, we incorporated these two indicators into the moderated mediation analysis procedure used to perform the hypothesis test.

\subsection{Moderated Mediation Test}

We first used the PROCESS Model 4 to test the mediating role of JS. As shown in Table 8 , POS significantly positively predicted JS $(\beta=0.57, t=14.62, p<0.001)$. Moreover, JS had a negative and significant effect on JB $(\beta=0.50, t=-4.14, p<0.001)$. The indirect effect of POS on JB through JS was also significant $(\beta=0.29, t=-2.50, p<0.01)$. The significant mediating effect was supported by the absence of zero within $95 \%$ confidence intervals $[(-0.48,-0.11)]$. The results indicated the existence of both a direct and an indirect effect (mediation). Therefore, JS partially mediated the relationship between POS and JB. The final mediating model explained $52 \%$ of the variance in JB $(\mathrm{ab} / \mathrm{c})$. Overall, hypotheses 1 and 2 were fully supported. Figure 2 shows the specific path coefficient among the variables.

Table 8. Results of the mediating effect of job satisfaction on the relationship between perceived organizational support and job burnout.

\begin{tabular}{cccccccccc}
\hline \multicolumn{2}{c}{ Path } & \multicolumn{3}{c}{ Overall Model Fit } & \multicolumn{3}{c}{ Regression Coefficient Significance } \\
\hline Outcome & Predictor & $\boldsymbol{R}$ & $\mathbf{R}^{\mathbf{2}}$ & $\boldsymbol{F}$ & $\boldsymbol{\beta}$ & $\boldsymbol{t}$ & LLCI & ULCI \\
\hline JS & POS & 0.71 & 0.51 & $213.84^{* * *}$ & 0.57 & $14.62^{* * *}$ & 0.49 & 0.65 \\
\hline JB & JS & 0.54 & 0.29 & $41.93^{* * *}$ & -0.50 & $-4.14^{* * *}$ & -0.74 & -0.26 \\
& POS & & & & -0.27 & $-2.79^{* *}$ & -0.46 & -0.08 \\
\hline \multicolumn{2}{c}{ Total effect } & 0.48 & 0.23 & $61.91^{* * *}$ & -0.56 & $-7.87^{* * *}$ & -0.70 & -0.42 \\
\hline \multicolumn{2}{c}{ Indirect effect } & & & & -0.29 & $-2.50^{* *}$ & -0.48 & -0.11 \\
\hline
\end{tabular}

${ }^{* *} p<0.01,{ }^{* * *} p<0.001$; POS: perceived organizational support, JS: job satisfaction, JB: job burnout, LLCI: lower limit confidence interval, ULCI: upper limit confidence interval. 


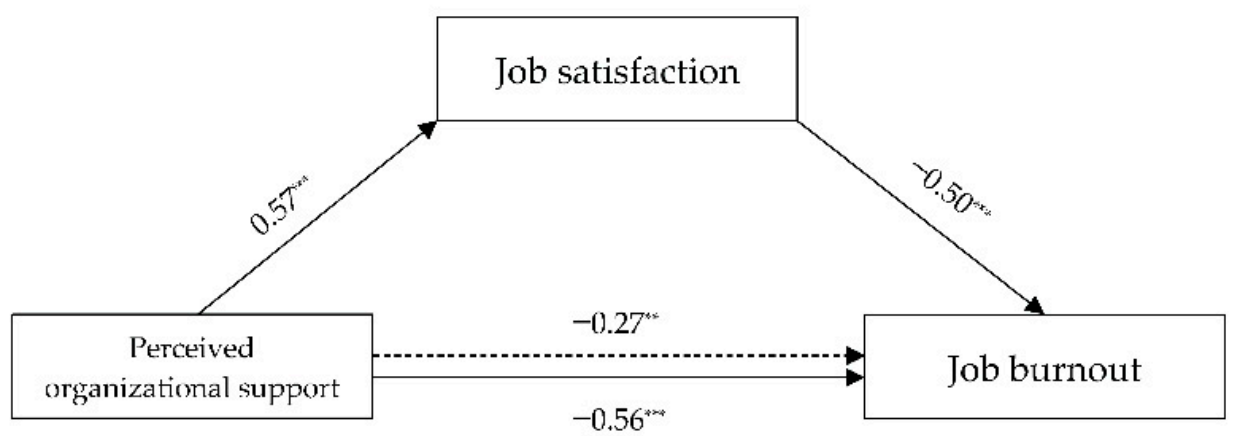

Figure 2. Mediation test. ${ }^{* *} p<0.01,{ }^{* * *} p<0.001$.

Next, we deployed the PROCESS Model 58 to test the total moderated mediating effects, following the suggestion of Hayes [73]. As shown in Table 9, in the direct path, POS negatively and significantly predicted JB $(\beta=-0.25, t=-2.64, p<0.01)$, indicating the presence of moderation. In the first half of the indirect path of moderation, POS positively and significantly predicted JS ( $\beta=0.49, t=12.81, p<0.001$ ); SE also positively significantly predicted JS $(\beta=0.32, t=6.23, p<0.00)$, but the interaction between POS and SE had no significant predictive effect on JS ( $\beta=0.11, t=1.83, p>0.05)$. This result indicated that SE did not play a moderating role in the association between POS and JS. In the latter half of the indirect path of moderation, JS negatively and significantly predicted JB $(\beta=-0.34$, $t=-2.63, p<0.01)$. SE also negatively and significantly predicted JB $(\beta=-0.46, t=-4.61$, $p<0.001)$, and the interaction between JS and SE positively and significantly predicted JB $(\beta=0.39, t=2.22, p<0.05)$. These results suggest that $\mathrm{SE}$ functioned as a moderator in the relationship between JS and JB. Hypothesis 3 was, therefore, partially supported. Figure 3 depicts the specific path coefficients among the variables.

Table 9. Results of the moderating effect of self-efficacy on the mediating role of job satisfaction in the relationship between perceived organizational support and job burnout.

\begin{tabular}{|c|c|c|c|c|c|c|c|c|}
\hline \multicolumn{2}{|c|}{ Regression Equation } & \multicolumn{3}{|c|}{ Overall Model Fit } & \multicolumn{4}{|c|}{ Regression Coefficient Significance } \\
\hline Outcome & Predictor & $R$ & $\mathbf{R}^{2}$ & $F$ & $\beta$ & $t$ & LLCI & ULCI \\
\hline \multirow[t]{3}{*}{ JS } & POS & 0.77 & 0.59 & $96.89 * * *$ & 0.49 & $12.81 * * *$ & 0.41 & 0.56 \\
\hline & SE & & & & 0.32 & $6.23^{* * *}$ & 0.22 & 0.41 \\
\hline & POS*SE & & & & 0.11 & 1.83 & -0.01 & 0.24 \\
\hline \multirow[t]{4}{*}{ JB } & JS & 0.60 & 0.36 & $23.37^{* * *}$ & -0.34 & $-2.63 * *$ & -0.59 & -0.09 \\
\hline & POS & & & & -0.25 & $-2.64 * *$ & -0.43 & -0.06 \\
\hline & SE & & & & -0.46 & $-4.61^{* * *}$ & -0.66 & -0.27 \\
\hline & $\mathrm{JS} * \mathrm{SE}$ & & & & 0.39 & $2.22 *$ & 0.04 & 0.75 \\
\hline
\end{tabular}

${ }^{*} p<0.05,{ }^{* *} p<0.01,{ }^{* * *} p<0.001$; POS: perceived organizational support, JS: job satisfaction, SE: self-efficacy, JB: job burnout, LLCI: lower limit confidence interval, ULCI: upper limit confidence interval.

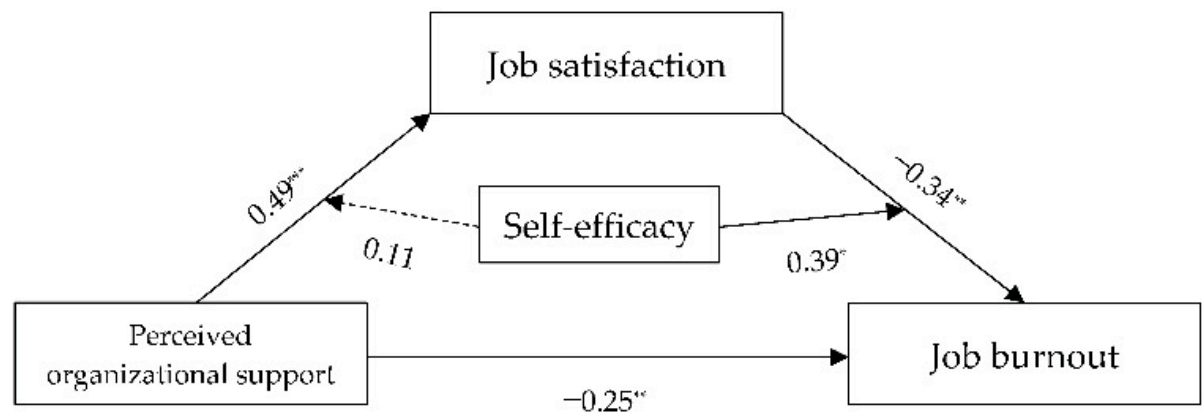

Figure 3. Moderated mediation test. ${ }^{*} p<0.05,{ }^{* *} p<0.01,{ }^{* * *} p<0.001$. 
Furthermore, we performed a simple slope to visualize the moderating effect of SE on the correlation between JS and JB. With the increase in SE, the predictive effect of JS on JB gradually declined (from [effect $=-0.56, t=-3.16, p<0.01,95 \% \mathrm{CI}=-0.91 ;-0.21$ ] to [effect $=-0.12, t=-0.82, p>0.05,95 \% \mathrm{CI}=-0.41 ; 0.17]$ ).

As shown in Figure 4, the conditional indirect effect of POS on JB through JS was statistically significant at the value of one standard deviation lower than the mean of self-efficacy (effect $=-0.24, S E=0.09,95 \% \mathrm{CI}=-0.43 ;-0.08$ ). However, this indirect effect was not significant at the value of one standard deviation above the mean of the moderator (effect $=-0.07, S E=0.13,95 \% \mathrm{CI}=-0.33 ; 0.16$ ). With an increase in the editors' sense of $\mathrm{SE}$, the indirect effect of POS on JB via JS was gradually weakened.

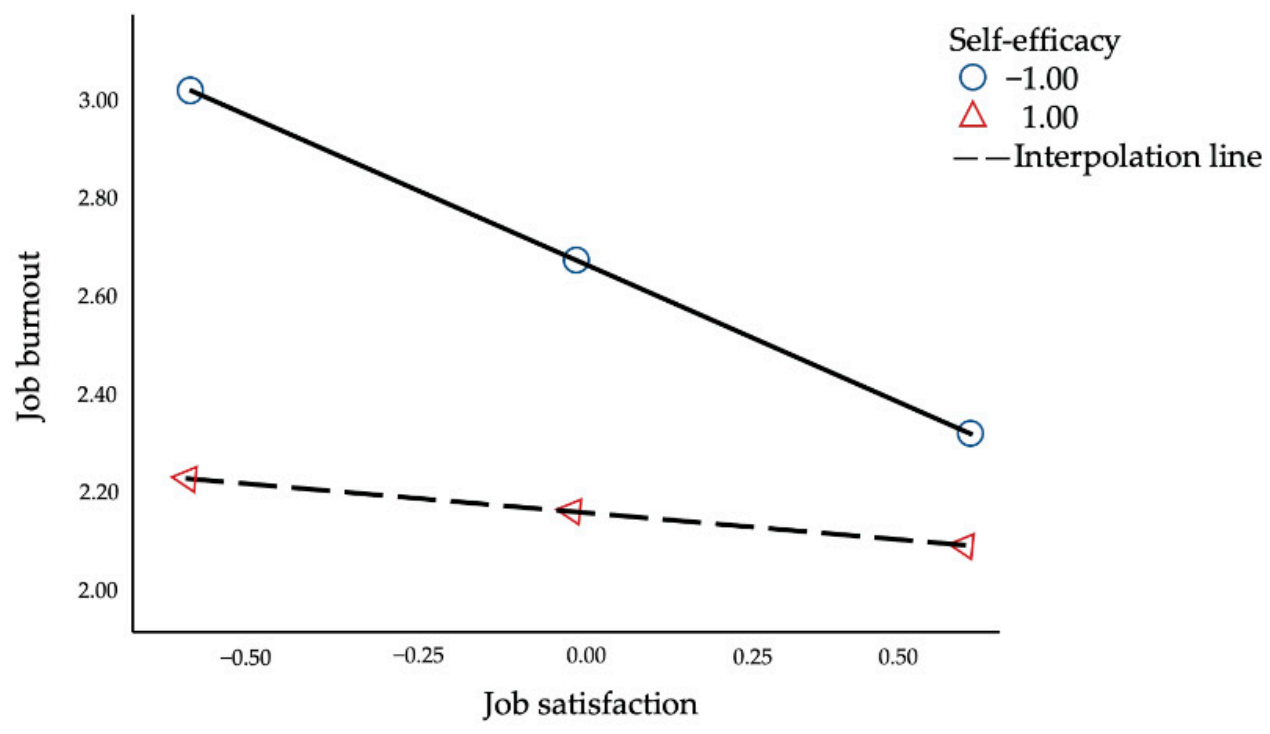

Figure 4. Simple plot image.

In sum, the moderated mediation model was partly established. JS acted as a mediator in the link between POS and JB. Moreover, SE served as a moderator in the association between JS and JB but did not play a moderating role in the relationship between POS and JS.

\section{Discussion}

In this study, we examined the moderating role of SE in the mediating effect of JS on the relationship between POS and JB among Chinese academic journal editors in the face of COVID-19. Participants' overall means were intermediate or above the midpoint of the scales, indicating that they were highly appreciated by their organizations, quite satisfied with their work conditions, and self-efficacious when achieving their tasks. However, the participants felt burned out due to repetitive work. These results are consistent with the finding that scientific journal editors had moderate degrees of satisfaction with their jobs and felt burnt out [34]. The results are also similar to the findings indicating that newspaper editors suffered moderate rates of emotional exhaustion and high rates of personal accomplishment $[74,75]$. However, these results appear incongruent with the argument that the COVID-19 pandemic and its restrictions can aggravate employees' feelings of burnout and fatigue [76,77]. This may be because being an academic journal editor is, by nature, a remote job that allows employees to work at home and online, thereby offering more flexibility, freedom, and safety in the case of COVID-19. Consequently, the current pandemic did not produce extra levels of anxiety and stress regarding the mandatory lockdowns, loss of income, or fear of unemployment and thus failed to accelerate their levels of burnout.

Furthermore, the significant difference analysis revealed that 31-40-year-old employees with 6-10 years of work experience had higher levels of burnout than their peers, 
similar to the empirical findings of Reinardy [78]. Except for differences in age, experience, and title, no significant differences were found in the control variables such as gender, position, or institute, unlike the findings asserting that employees who are female [35,79], work at a small firm, and/or work as a copy editor [75,80-85] are more vulnerable to burnout than others. This result indicated that middle-aged academic journal editors who struggled in their early careers were more likely to experience burnout. Hence, more job resources and support should be provided for these editors to enhance their SE and JS and mitigate their JB.

In addition, the results presented close links between POS, JS, SE, and JB among Chinese academic journal editors. The specific interrelationship between the four observed variables is discussed explicitly in the following subsections.

\subsection{The Relationship between POS and JB}

The results indicated that POS had a significant negative correlation with all dimensions of JB and could significantly and negatively predict JB. This indicates that the higher the POS levels of Chinese academic journal editors, the lower their JB.

This result is consistent with previous theoretical arguments $[9,86]$. According to the JDR model [7], organizational support is essential in minimizing JB syndrome. Moreover, providing employees with necessary organizational support can help employees effectively tackle strained work situations [87]. When perceiving desirable levels of support from their organizations, employees may feel more effective and less monotonous when coping with repetitive work tasks. Conversely, reducing POS may increase employees' JB. This study also found that, regardless of their characteristics, Chinese academic journal editors who perceived support from their organizations had a comparatively low level of JB. This result is also in line with the empirical findings that reported a negative correlation between POS and all JB components-namely, the higher the POS, the lower the JB [88-91]. For instance, Reinardy [82] found that broadcast journalists perceiving a low level of organizational support had significantly higher levels of burnout. Based on these findings, it can be inferred that POS is a vital predictor for JB that should be considered when committing to diminish levels of JB among Chinese academic journal editors. Thus, affected stakeholders, including journals, industries, associations, and universities, can mitigate editors' JB by providing the organizational support that editors want. These stakeholders also need to consider the dynamics and diversity of organizational support by improving working environments, raising wages, and ameliorating the setbacks that would be detrimental to position promotion and work accomplishment.

\subsection{The Mediating Role of JS}

The results confirmed that JS could act as a mediator between POS and JB among Chinese academic journal editors; that is, the impact of POS on JB could be partly direct and partly indirect, through JS.

This result is congruent with the findings that the organizational support perceived by employees plays a critical role in predicting and promoting JS [92,93]. Employees with high levels of POS presented greater satisfaction with their jobs [86]. According to social exchange theory [20,21], when perceiving strong support from an organization, employees tend to reciprocate by engaging in their jobs and developing loyalty to their organization [25]. In comparison, employees feeling unsupported are likely to feel dissatisfied with their jobs and reduce their commitment to the organization [94]. Therefore, when the organization's assistance meets Chinese academic journal editors' needs for recognition, the JS will increase among this group of workers [29].

This result also agrees with the assumption of Maslach, Schaufeli, and Leiter [1] that a drop in satisfaction serves as a precursor to burnout. Likewise, Cook and Banks [95] found that JS was significantly negatively related to JB among copy editors working at a small newspaper in the United States. This result is also in line with Liu and Lo [96], who stated 
that JS is negatively related to JB among Taiwanese reporters and acts as a mediator in burnout and turnover intention.

Academic journal editors experience an increased risk of stress in their profession due to deadlines, the need for a low rate of word inaccuracy, and ongoing updates to technology [97]. This situation is much more challenging for Chinese academic journal editors, for whom the rate of acceptable content inaccuracy was decreased from below $0.03 \%$ to below $0.02 \%$ in the latest Regulation on the Quality of Newspapers and Journals [98]. Moreover, these editors feel stressed and exhausted about the annual journal evaluation outcomes from assessment institutes, which determine whether their journals will be abstracted by the Chinese Social Science Citation Index and the Social Science Citation Index of Web of Science. A higher ranking can bring many benefits to journals, such as greater financial support and faster promotions for editors. However, editors who work at ordinary journals may have fewer opportunities to realize their own career aspirations, with a high risk of being fired. Many editors have expressed strong intentions to leave the article-publishing industry, with high levels of emotional exhaustion and depersonalization, and low levels of personal accomplishment [99]. Therefore, industry practitioners should consider the importance of avoiding academic journal editor JB by improving editors satisfaction with their overall job situation and promoting the availability of organizational support. When academic journal editors have strong perceptions of their contributions being valued and their wellbeing being cared for, the editors are more satisfied with their work and can overcome the feelings of burnout.

However, it is worth noting that POS still had a significant direct effect on JB, which indicated that JS was only a partial mediator. Complete mediation can be established in theory but would be rare. Moreover, there may be other variables that were not considered in this study.

\subsection{The Moderating Role of SE}

This study also indicated that, in the indirect effect of POS on JB via JS, SE significantly moderated only the latter half of the relationship between JS and JB. The conditional effect outcome showed a transitional point along the continuum of the moderator between statistically significant and nonsignificant. Specifically, when Chinese academic journal editors' sense of SE was low, the negatively predictive effect of JS on JB was strong; when the Chinese academic journal editors' sense of SE was high, the negatively predictive effect of JS on JB was weakened.

This result further confirmed the social cognitive theory [56,100], which theorizes that both individual disposition and organizational factors influence work performance and attitude. This result also coincides with the argument that employees' inefficacy may lead to job dissatisfaction and burnout $[4,100]$. In this study, Chinese academic journal editors' SE significantly negatively moderated the effect of JS on JB. However, we noted that the moderating role of $\mathrm{SE}$ at a low level was more robust than that at a high level. This result could be due to the protective effect of SE [101,102]. When employees perceive that they have efficient organizational support and feel satisfied with their work, which can significantly overcome feelings of burnout, those employees are prone to mobilizing fewer individual resources such as SE. However, if Chinese academic journal editors are dissatisfied with their organizational support and job conditions, they are at high risk of experiencing JB even with a high level of SE. Therefore, the organizations should focus on individual-level intervention strategies to enhance employees' work-related abilities to cope with work stressors [34], including the development of coping skills [103], the promotion of healthy work-life patterns [104], and the restructuring of irrational beliefs [105].

However, the present results do not completely support the JDR model, which proposes that POS influences JS through SE [24]. Unlike the previous finding that employees' SE could significantly promote the positive effect of POS on JS [11], the results in the current research instead indicate that Chinese academic journal editors' SE had no moderating effect on the predictive effects of POS on JS. Given the relatively low correlation between 
SE and POS $(r=0.32)$, this remarkable result could be explained by the social cognitive theory that proposes that, when employees lack confidence in their abilities to achieve their work aspirations or lack the desired opportunities and support needed to take responsibility and increase their dedication, those workers will feel unaccomplished and dissatisfied with their jobs. Therefore, despite the gap between the hypothesized model and the empirical path, organizations also need to focus on organizational-level intervention strategies, involving reducing workload [106], improving the organizational climate [107], and identifying and providing the personalized and diverse support that employees desire. These strategies will increase confidence among employees in successfully fulfilling their work obligations and further improve their JS.

\section{Limitations and Further Work}

While the reliability and validity issues of the model were verified in the current study, there are a few limitations that must be acknowledged. The first limitation is that the data were gathered by self-reporting. Therefore, causality and generalization in the results should be treated with caution. Nevertheless, the results suggest common scenarios among Chinese academic journal editor cohorts. The second limitation is that although the sample was deemed representative, the sample size was still small, constraining the generalizability of the findings. Further research is needed to enlarge the sample size and improve the statistical effect size post-COVID-19. The third limitation is that we did not consider controlled variables when validating the model, which may have resulted in statistical bias. Future work should incorporate more controlled variables, such as age, title, and work experience, which show differences in the levels of their constructs, to enhance the statistical power and model discrimination.

\section{Conclusions}

This study aimed to design a moderated mediation model in which POS, JS, SE, and JB were tested among Chinese academic journal editors, drawing on social cognitive theory, social exchange theory, and the JDR model. The results revealed that POS is a critical antecedent when predicting JB and JS. The results also showed that JS partially mediated the impact of POS on JB. Although SE only moderated the relationship between JS and JB, the total moderating effect was significant. Notably, the moderating role of SE at the low level was stronger than that at a high level. This empirical result adds value to the current literature on employees' emotional and psychological health in the academic publishing industry. This research also provides an informative insight into how to provide academic journal editors with their desired level of organizational support, accelerate their SE, and boost their satisfaction with their jobs in the face of the COVID-19 pandemic by offering more opportunities to develop their professional skills and more flexible career promotion options. This study could be further strengthened and generalized by amplifying the sample size and diversity to increase the effect size and decrease random errors.

Author Contributions: S.W. was the PI for the project. X.Y. and L.Y. developed the questionnaires. X.Y. and S.Z. collected the data. S.W., W.C., W.Z. and M.H. analyzed the data and validated the model. S.W., X.Y., W.C. and W.Z. interpreted the results. S.W., S.Z. and M.H developed the tables and visualized the figures. S.W., S.Z., W.C., W.Z., M.H. and L.Y. wrote and reviewed the paper. S.W. acquired the funding. All authors have read and agreed to the published version of the manuscript.

Funding: This research was funded by the National Education Science Planning Program: BOA200048, Guangdong Social Science Fund, grant number, GD18XJY22, and Guangzhou Social Science Fund, grant number, 2020GZGJ63.

Institutional Review Board Statement: The study was approved by the South China Normal University Academic Ethics Committee.

Informed Consent Statement: Informed consent was obtained from all participants involved in the study. 
Data Availability Statement: The data that support the findings of this study are available from the corresponding author with the permission of South China Normal University, upon request. Restrictions apply to the availability of these data, which were used under license for this study.

Acknowledgments: The authors would like to thank the reviewers for their valuable comments on the manuscript.

Conflicts of Interest: The authors declare no conflict of interest.

\section{References}

1. Maslach, C.; Schaufeli, W.B.; Leiter, M.P. Job burnout. Annu. Rev. Psychol. 2001, 52, 397-422. [CrossRef]

2. Maslach, C.; Jackson, S.E. The measurement of experienced burnout. J. Organ. Behav. 1981, 2, 99-113. [CrossRef]

3. Hassan, O.; Ibourk, A. Burnout, self-efficacy and job satisfaction among primary school teachers in Morocco. Soc. Sci. Humanit. Open 2021, 4, 100148. [CrossRef]

4. Betoret, F.D. Self-efficacy, school resources, job stressors and burnout among Spanish primary and secondary school teachers: A structural equation approach. Educ. Psychol. 2009, 29, 45-68. [CrossRef]

5. Mikolajczak, M.; Raes, M.-E.; Avalosse, H.; Roskam, I. Exhausted Parents: Sociodemographic, Child-Related, Parent-Related, Parenting and Family-Functioning Correlates of Parental Burnout. J. Child Fam. Stud. 2017, 27, 602-614. [CrossRef]

6. Green, A.E.; Albanese, B.J.; Shapiro, N.M.; Aarons, G.A. The roles of individual and organizational factors in burnout among community-based mental health service providers. Psychol. Serv. 2014, 11, 41-49. [CrossRef] [PubMed]

7. Demerouti, E.; Bakker, A.B.; Nachreiner, F.; Schaufeli, W.B. The job demands-resources model of burnout. J. Appl. Psychol. 2001, 86, 499-512. [CrossRef] [PubMed]

8. Purvanova, R.K.; Muros, J.P. Gender differences in burnout: A meta-analysis. J. Vocat. Behav. 2010, 77, 168-185. [CrossRef]

9. Eisenberger, R.; Huntington, R.; Hutchison, S.; Sowa, D. Perceived organizational support. J. Appl. Psychol. 1986, 71 , 500-507. [CrossRef]

10. Özyer, K.; Berk, A.; Polatc, S. Does the Perceived Organizational Support Reduce Burnout? A Survey on Turkish Health Sector. Int. J. Bus. Adm. Manag. Res. 2016, 2, 22-27.

11. Zeng, X.; Zhang, X.; Chen, M.; Liu, J.; Wu, C. The Influence of Perceived Organizational Support on Police Job Burnout: A Moderated Mediation Model. Front Psychol. 2020, 11, 948. [CrossRef]

12. Altamimi, F.A.; Alsubaie, S.S.; Nasaani, A.A. Why So Cynical? The Effect of Job Burnout as a Mediator on the Relationship Between Perceived Organizational Support and Organizational Cynicism. Eur. J. Bus. Manag. 2021, 13, 32-43. [CrossRef]

13. Locke, E.A. The nature and causes of job satisfaction. In Handbook of Industrial \& Organizational Psychology; Dunnette, M.C., Ed.; Rand McNally: Chicago, IL, USA, 1976; pp. 1279-1349.

14. Weiss, D.J.; Dawis, R.V.; England, G.W. Manual for the Minnesota Satisfaction Questionnaire. Minn. Stud. Vocat. Rehabil. 1967, 22,120 .

15. Blaauw, D.; Ditlopo, P.; Maseko, F.; Chirwa, M.; Mwisongo, A.; Bidwell, P.; Thomas, S.; Normand, C. Comparing the job satisfaction and intention to leave of different categories of health workers in Tanzania, Malawi, and South Africa. Glob Health Action 2013, 6, 19287. [CrossRef] [PubMed]

16. Dolan, S.N. The relationship between burnout and job satisfaction in nurses. J. Adv. Nurs. 1987, 12, 3-12. [CrossRef]

17. Rouleau, D.; Fournier, P.; Philibert, A.; Mbengue, B.; Dumont, A. The effects of midwives' job satisfaction on burnout, intention to quit and turnover: A longitudinal study in Senegal. Hum. Resour. Health 2012, 10, 9. [CrossRef] [PubMed]

18. Wang, H.; Jin, Y.; Wang, D.; Zhao, S.; Sang, X.; Yuan, B. Job satisfaction, burnout, and turnover intention among primary care providers in rural China: Results from structural equation modeling. BMC Fam. Pract. 2020, 21, 12. [CrossRef]

19. Bandura, A. Self-efficacy: Toward a Unifying Theory of Behavioral Change. Psychol. Rev. 1977, 84, 191-215. [CrossRef]

20. Blau, P. Exchange and Power in Social Life; Wiley: New York, NY, USA, 1964.

21. Gouldner, A.W. The norm of reciprocity: A preliminary statement. Am. Sociol. Rev. 1960, 25, 161-178. [CrossRef]

22. Yuh, J.; Choi, S. Sources of social support, job satisfaction, and quality of life among childcare teachers. Soc. Sci. J. 2017, 54, 450-457. [CrossRef]

23. McGinty, A.S.; Justice, L.; Rimm-Kaufman, S.E. Sense of School Community for Preschool Teachers Serving At-Risk Children. Early Educ. Dev. 2008, 19, 361-384. [CrossRef]

24. Bakker, A.B.; Hakanen, J.J.; Demerouti, E.; Xanthopoulou, D. Job resources boost work engagement, particularly when job demands are high. J. Educ. Psychol. 2007, 99, 274-284. [CrossRef]

25. Wu, S.; Zhou, S.; Yu, X.; Chen, W.; Zheng, W.; Huang, M.; Zhang, H.; Li, X.; Fang, G.; Zhao, X.; et al. Association Between Social Support and Job Satisfaction Among Mainland Chinese Ethnic Minority Kindergarten Teachers: The Mediation of Self-Efficacy and Work Engagement. Front. Psychol. 2020, 11, 581397. [CrossRef] [PubMed]

26. Karademas, E.C. Self-efficacy, social support and well-being: The mediating role of optimism. Pers. Individ. Differ. 2006, 40, 1281-1290. [CrossRef]

27. Schaufeli, W.B.; Greenglass, E.R. Introduction to special issue on burnout and health. Psychol. Health 2001, 16, 501-510. [CrossRef]

28. Raižienè, S.; Bakšytè, A. Socialines paslaugas teikiančiu darbuotoju perdegimo sindromo, socialinès paramos bei saviveiksmingumo sąsajos. Soc. Darb. 2010, 9, 119-126. 
29. Xu, Z.; Yang, D.; Chen, B. Career Difficulties That Chinese Academic Journal Editors Face and Their Causes. J. Sch. Publ. 2021, 52, 212-232. [CrossRef]

30. Kanehvo, E.; Ferrier, P. Professor and Editor Trade Places to Avoid Burnout. J. Mass Commun. Educ. 1998, 53, 83-91. [CrossRef]

31. Ainsworth, M. How can publishers support early career journal editors? Learn. Publ. 2019, 32, 291-292. [CrossRef]

32. Sabbah, I.; Sabbah, H.; Sabbah, S.; Akoum, H.; Droubi, N. Burnout among Lebanese nurses: Psychometric properties of the Maslach Burnout Inventory-Human Services Survey (MBI-HSS). Health 2012, 4, 644-652. [CrossRef]

33. Wang, L.F. Job burnout and intervention for academic journal editors. China Publ. J. 2014, 13, 65-68.

34. Yu, Y.; Zhang, J.B. Job burnout and influencing factors of sci-tech journal editors. Acta Ed. 2004, 16, 11-12. [CrossRef]

35. Yao, R.B.; Yu, H.J.; Liu, C.; Zhang, X.S.; Liu, L.; Zhou, Y.; Ma, Q. The relationship between job burnout, social support, and mental health among journal editors in Anhui Province. Acta Ed. 2015, 27, 400-403. [CrossRef]

36. Fessell, D.; Cherniss, C. Coronavirus Disease 2019 (COVID-19) and Beyond: Micropractices for Burnout Prevention and Emotional Wellness. J. Am. Coll. Radiol. 2020, 17, 746-748. [CrossRef]

37. Griffith, A.K. Parental Burnout and Child Maltreatment During the COVID-19 Pandemic. J. Fam. Violence 2020, 1-7. [CrossRef]

38. Kannampallil, T.G.; Goss, C.W.; Evanoff, B.A.; Strickland, J.R.; McAlister, R.P.; Duncan, J. Exposure to COVID-19 patients increases physician trainee stress and burnout. PLoS ONE 2020, 15, e0237301. [CrossRef]

39. Yildirim, M.; Solmaz, F. COVID-19 burnout, COVID-19 stress and resilience: Initial psychometric properties of COVID-19 Burnout Scale. Death Stud 2020, 1-9. [CrossRef]

40. Kleinberg, E. Academic Journals in the Digital Era: An Editor's Reflections. Perspect. Hist. 2012, 12.

41. Settoon, R.P.; Bennett, N.; Liden, R.C. Social exchange in organizations: Perceived organizational support, leader-member exchange, and employee reciprocity. J. Appl. Psychol. 1996, 81, 219-227. [CrossRef]

42. Hekman, D.R.; Bigley, G.A.; Steensma, H.K.; Hereford, J.F. Combined Effects of Organizational And Professional Identification on the Reciprocity Dynamic for Professional Employees. Acad. Manag. J. 2009, 52, 506-526. [CrossRef]

43. Shen, J.; Benson, J. When CSR Is a Social Norm:How Socially Responsible Human Resource Management Affects Employee Work Behavior. J. Manag. 2016, 42, 1723-1746. [CrossRef]

44. Jiang, J.; Xu, Y.; Zhang, S.; Chen, L. Job Burnout of Psychological Counselors. Chin. Ment. Health J. 2004, 18, 854-855. [CrossRef]

45. Jiang, J.; Xu, Y.; Lin, D. The Relationship of Medical Staff's Job Burnout with Type A Personality and Locus of Control. Psychol. Sci. 2004, 27, 364-366. [CrossRef]

46. Hoppock, R. Job Satisfaction; Harper and Brothers: New York, NY, USA, 1935.

47. Spector, P.E. Job Satisfaction: Application, Assessment, Cause, and Consequences; Sage Publications: Thousand Oaks, CA, USA, 1997.

48. Koelbel, P.W.; Fuller, S.G.; Misener, T.R. An Explanatory Model of Nurse Practitioner Job Satisfaction. J. Am. Acad. Nurse Pract. 1991, 3, 17-24. [CrossRef] [PubMed]

49. Xiao, Y.; Wang, J.; Chen, S.; Wu, Z.; Cai, J.; Weng, Z.; Li, C.; Zhang, X. Psychological distress, burnout level and job satisfaction in emergency medicine: A cross-sectional study of physicians in China. Emerg. Med. Australas. 2014, 26, 538-542. [CrossRef]

50. Ge, C.; Fu, J.; Chang, Y.; Wang, L. Factors associated with job satisfaction among Chinese community health workers: A crosssectional study. BMC Public Health 2011, 11, 884. [CrossRef] [PubMed]

51. Zhang, J.X.; Schwarzer, R. Measuring optimistic self-beliefs: A Chinese adaptation of the General Self-Efficacy Scale. Psychologia 1995, 38, 174-181.

52. Schwarzer, R.; BaBler, J.; Kwiatek, P.; Schroder, K.; Zhang, J.X. The Assessment of Optimistic Self-beliefs: Comparison of the German, Spanish, and Chinese Versions of the General Self-efficacy Scale. Appl. Psychol. Int. Rev. 1997, 46, 69-88. [CrossRef]

53. Jerusalem, M.; Schwarzer, R. Self-efficacy as a resource factor in stress appraisal processes. In Self-Efficacy: Thought Control of Action; Schwarzer, R., Ed.; Hemisphere: Washington, DC, USA, 1992.

54. Schwarzer, R.; Mueller, J.; Greenglass, E. Assessment of perceived general self-efficacy on the internet: Data collection in cyberspace. Anxiety Stress Coping 1999, 12, 145-161. [CrossRef]

55. Schwarzer, R.; Born, A.; Iwawaki, S.; Lee, Y.M. The Assessment of Optimistic Self-Beliefs: Comparison of the Chinese, Indonesian, Japanese, and Korean Versions of the General Self-Efficacy Scale. Psychologia 1997, 40, 1-13.

56. Cheung, S.-K.; Sun, S.Y.K. Assessment of Optimistic Self-Beliefs: Further Validation of the Chinese Version of the General Self-Efficacy Scale. Psychol. Rep. 1999, 85, 1221-1224. [CrossRef]

57. Podsakoff, P.M.; MacKenzie, S.B.; Lee, J.Y.; Podsakoff, N.P. Common method biases in behavioral research: A critical review of the literature and recommended remedies. J. Appl. Psychol. 2003, 88, 879-903. [CrossRef] [PubMed]

58. Hair, J.F.; Hult, G.T.M.; Ringle, C.; Sarstedt, M. A Primer on Partial Least Squares Structural Equation Modeling (PLS-SEM); Sage Publications: New York, NY, USA, 2017.

59. Hair, J.F.; Black, W.C.; Babin, B.J.; Anderson, R.E. Multivariate Data Analysis; Pearson Education Limited: London, UK, 2013.

60. Hair, J.F.; Sarstedt, M.; Ringle, C.M.; Mena, J.A. An assessment of the use of partial least squares structural equation modeling in marketing research. J. Acad. Mark. Sci. 2012, 40, 414-433. [CrossRef]

61. Maslach, C.; Leiter, M.P. Understanding the burnout experience: Recent research and its implications for psychiatry. World Psychiatry 2016, 15, 103-111. [CrossRef] [PubMed]

62. Roldán, J.L.; Sánchez-Franco, M.J. Variance-based structural equation modeling: Guidelines for using partial least squares in information systems research. In Research Methodologies, Innovations and Philosophies in Software Systems Engineering and Information Systems; IGI Global: Hershey, PA, USA, 2012. 
63. Carmines, E.G.; Zeller, R.A. Reliability and Validity Assessment; Sage Publications: Thousand Oaks, CA, USA, 1979.

64. Fornell, C.; Larcker, D.F. Evaluating structural equation models with unobservable variables and measurement error. J. Mark. Res. 1981, 18, 39-50. [CrossRef]

65. MacCallum, R.; Tucker, L. Representing sources of error in the common-factor model: Implications for theory and practice. Psychol. Bull. 1991, 109, 502-511. [CrossRef]

66. MacCallum, R.C.; Widaman, K.F.; Preacher, K.J.; Hong, S. Sample Size in Factor Analysis: The Role of Model Error. Multivar. Behav. Res. 2001, 36, 611-617. [CrossRef] [PubMed]

67. Henseler, J.; Ringle, C.M.; Sarstedt, M. A new criterion for assessing discriminant validity in variance-based structural equation modeling. J. Acad. Mark. Sci. 2015, 43, 115-135. [CrossRef]

68. Kline, R.B. Principles and Practice of Structural Equation Modeling; Guilford Publications: New York, NY, USA, 2015.

69. Dijkstra, T.K.; Henseler, J. Consistent and asymptotically normal PLS estimators for linear structural equations. Comput. Stat. Data Anal. 2015, 81, 10-23. [CrossRef]

70. Hooper, D.; Coughlan, J.; Mullen, M. Structural equation modelling: Guidelines for determining model fit. Electron. J. Bus. Res. Methods 2008, 6, 53-60. [CrossRef]

71. Henseler, J.; Dijkstra, T.K.; Sarstedt, M.; Ringle, C.M.; Diamantopoulos, A.; Straub, D.W.; Ketchen, D.J.; Hair, J.F.; Hult, G.T.M.; Calantone, R.J. Common Beliefs and Reality About PLS: Comments on Rönkkö and Evermann (2013). Organ. Res. Methods 2014, 17, 182-209. [CrossRef]

72. Chin, W.W. The partial least squares approach to structural equation modeling. In Modern Methods for Business Research; Marcoulides, G.A., Ed.; Psychology Press: London, UK, 1998; pp. 295-336.

73. Hayes, A.F. Introduction to Mediation, Moderation, and Conditional Process Analysis: A Regression-Based Approach; The Guilfrd Press: New York, NY, USA; London, UK, 2017.

74. Reinardy, S. It's gametime: The Maslach Burnout Inventory measures burnout of sports journalists. J. Mass Commun. Q. 2006, 83, 397-412. [CrossRef]

75. Filak, V.F.; Reinardy, S. Editor toast: A study of burnout and job satisfaction among college newspaper editors. J. Mass Commun. Educ. 2011, 66, 243-256. [CrossRef]

76. Morgantini, L.A.; Naha, U.; Wang, H.; Francavilla, S.; Acar, O.; Flores, J.M.; Crivellaro, S.; Moreira, D.; Abern, M.; Eklund, M.; et al. Factors contributing to healthcare professional burnout during the COVID-19 pandemic: A rapid turnaround global survey. PLoS ONE 2020, 15, e0238217. [CrossRef]

77. Giorgi, G.; Lecca, L.I.; Alessio, F.; Finstad, G.L.; Bondanini, G.; Lulli, L.G.; Arcangeli, G.; Mucci, N. COVID-19-Related Mental Health Effects in the Workplace: A Narrative Review. Int. J. Environ. Res. Public Health 2020, 17, 7857. [CrossRef]

78. Reinardy, S. Satisfaction vs. Sacrifice: Sports Editors Assess the Influences of Life Issues on Job Satisfaction. J. Mass Commun. Q. 2007, 84, 105-121. [CrossRef]

79. Reinardy, S. Female journalists more likely to leave newspapers. Newsp. Res. J. 2009, 30, 42-57. [CrossRef]

80. Reinardy, S. Survey measures burnout in newspaper sports editors. Newsp. Res. J. 2008, 29, 40-54.

81. Reinardy, S. TV Sportscasters 1, Burnout 0: Resources Sideline the Job Stressors of Sports Broadcasters. J. Sports Media 2012, 7, 89-107. [CrossRef]

82. Reinardy, S. Boom or Bust? U.S. Television News Industry is Booming But Burnout Looms for Some. J. Media Bus. Stud. 2015, 10, 23-40. [CrossRef]

83. Cook, B.B.; Banks, S.R.; Turner, R.J. The effects of work environment on burnout in the newsroom. Newsp. Res. J. 1993, 14, 123-136. [CrossRef]

84. Craig, D.A. Influences on editing quality at the Daily Oklahoman. Newsp. Res. J. 1999, 20, 58-71. [CrossRef]

85. Richardsen, A.M.; Martinussen, M. Factorial validity and consistency of the MBI-GS across occupational groups in Norway. Int. J. Stress Manag. 2005, 12, 289-297. [CrossRef]

86. Arefin, M.S.; Raquib, M.; Arif, I. The relationship between high performance work systems and proactive behaviors: The mediating role of perceived organizational support. Eur. Sci. J. 2015, 11, 314-327.

87. Stinglhamber, F.; Vandenberghe, C. Organizations and supervisors as sources of support and targets of commitment: A longitudinal study. J. Organ. Behav. 2003, 24, 251-270. [CrossRef]

88. Cropanzano, R.; Howes, J.C.; Grandey, A.A.; Toth, P. The Relationship of Organizational Politics and Support to Work Behaviors, Attitudes, and Stress. J. Organ. Behav. 1997, 18, 159-180. [CrossRef]

89. Armstrong-Stassen, M. The influence of prior commitment on the reactions of layoff survivors to organizational downsizing. J. Occup. Health Psychol. 2004, 9, 46-60. [CrossRef] [PubMed]

90. Bobbio, A.; Bellan, M.; Manganelli, A.M. Empowering leadership, perceived organizational support, trust, and job burnout for nurses: A study in an Italian general hospital. Health Care Manag. Rev. 2012, 37, 77-87. [CrossRef]

91. Yaghoubi, N.M.; Pourghaz, A.; Toomaj, H.G. Study of Perceived Organizational Support's Relationship with Job Burnout. Int. J. Acad. Res. Bus. Soc. Sci. 2014, 4, 315. [CrossRef]

92. Zhang, L.; Lin, Y.; Wan, F. Social support and job satisfaction: Elaborating the mediating role of work-family interface. Curr. Psychol. 2015, 34, 781-790. [CrossRef]

93. Ferguson, M.; Carlson, D.; Zivnuska, S.; Whitten, D. Support at work and home: The path to satisfaction through balance. J. Vocat. Behav. 2012, 80, 299-307. [CrossRef] 
94. Lambert, E.G.; Minor, K.I.; Wells, J.B.; Hogan, N.L. Social support's relationship to correctional staff job stress, job involvement, job satisfaction, and organizational commitment. Soc. Sci. J. 2016, 53, 22-32. [CrossRef]

95. Cook, B.B.; Banks, S.R. Predictors of Job Burnout in Reporters and Copy Editors. J. Q. 1993, 70, 108-117. [CrossRef]

96. Liu, H.-L.; Lo, V.-H. An integrated model of workload, autonomy, burnout, job satisfaction, and turnover intention among Taiwanese reporters. Asian J. Commun. 2018, 28, 153-169. [CrossRef]

97. Weaver, D.H.; Willnat, L.; Wilhoit, G.C. The American journalist in the digital age: Another look at US news people. J. Mass Commun. Q. 2019, 96, 101-130. [CrossRef]

98. Adminstration, N.P.a.P. Regulation on the Quality of Newspaper and Journal. Available online: http://www.nppa.gov.cn/nppa/ contents /279/74416.shtml (accessed on 9 September 2021).

99. Reinardy, S. Newspaper journalism in crisis: Burnout on the rise, eroding young journalists' career commitment. Journalism 2011, 12, 33-50. [CrossRef]

100. Bandura, A. Self-Efficacy in Changing Societies; Cambridge University Press: Cambridge, NY, USA, 1995.

101. Yuan, M.; Guo, X.; Li, X.; Chen, X.; Wang, C.; Li, Y. The moderating role of regulatory emotional self-efficacy on smoking craving: An ecological momentary assessment study. Psych. J. 2018, 7, 5-12. [CrossRef] [PubMed]

102. Bandura, A.; Caprara, G.V.; Barbaranelli, C.; Gerbino, M.; Pastorelli, C. Role of Affective Self-Regulatory Efficacy in Diverse Spheres of Psychosocial Functioning. Child Dev. 2003, 74, 769-782. [CrossRef]

103. Maslach, C.; Goldberg, J. Prevention of burnout: New perspectives. Appl. Prev. Psychol. 1998, 7, 63-74. [CrossRef]

104. Le Blanc, P.M.; Hox, J.J.; Schaufeli, W.B.; Taris, T.W.; Peeters, M.C. Take care! The evaluation of a team-based burnout intervention program for oncology care providers. J. Appl. Psychol. 2007, 92, 213-227. [CrossRef] [PubMed]

105. Van Rhenen, W.; Blonk, R.W.; van der Klink, J.J.; van Dijk, F.J.; Schaufeli, W.B. The effect of a cognitive and a physical stressreducing programme on psychological complaints. Int. Arch. Occup. Environ. Health 2005, 78, 139-148. [CrossRef] [PubMed]

106. Gregory, S.T.; Menser, T.; Gregory, B.T. An Organizational Intervention to Reduce Physician Burnout. J. Healthc. Manag. 2018, 63, 338-352. [CrossRef] [PubMed]

107. Maslach, C.; Leiter, M.P.; Jackson, S.E. Making a significant difference with burnout interventions: Researcher and practitioner collaboration. J. Organ. Behav. 2012, 33, 296-300. [CrossRef] 